\title{
Investigation of the effects of St. John's wort (Hypericum perforatum) oil on the methotrexate-induced gastrointestinal mucosa injury and hepatotoxicity in mice
}

\author{
Mansur Seymen Seğmenoğlu, Harun Akıll1²
}

\author{
${ }^{1}$ Department of Nursing, Faculty of Health Sciences, Osmaniye Korkut Ata University, Osmaniye/TURKEY \\ ${ }^{2}$ Provincial Directorate of Agriculture and Forestry, Adana/TURKEY
}

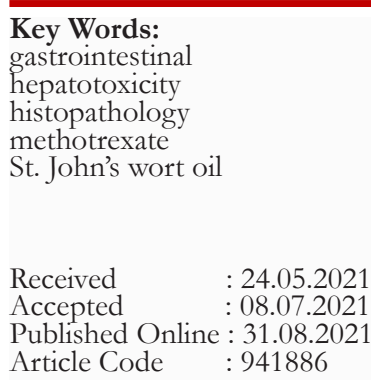

Correspondence:

MS SEĞMENOĞLU

(mansursegmenoglu@osmaniye.edu.tr)

ORCID

MS SEĞMENOĞLU : 0000-0003-2743-6245 H. AKILLI : :0000-0002-8086-556X

\begin{abstract}
St. John's wort oil is a herbal product that has therapeutic features. Our aim in this study is to investigate the effects of St. John's wort oil on irritated gastrointestinal mucosa and liver. The study is based on experimental animal trials. 21 healthy swiss albino mice were randomly divided into three groups: control group, group-2, group-3. The single dose of methotrexate $(20 \mathrm{mg} / \mathrm{kg})$ was given intraperitoneally on the 1 st day to the group- 2 and group- 3 . St. John's wort oil $(4 \mathrm{ml} / \mathrm{kg})$ was given by gavages into the stomach daily for 7 days to the group-3. Following the necropsy, the gastrointestinal mucosa samples and the liver tissue samples were collected for histopathological evaluation. No pathological changes were found in the gastrointestinal mucosa and liver of control group. No pathological changes were found in the mice of group-3 in histopathological examination of the gastric mucosa. Significant hyperplasia and mononuclear cell infiltrations in lamina propria were observed in the mice of the group-2's intestinal mucosa. The group-3 mice's intestinal mucosa was similar to control group's intestinal mucosa. In liver histopathology, mononuclear cell infiltrates with locally degenerative changes in the periportal area, thrombotic changes in the vessels, bile duct hyperplasia, megalocytosis in hepatocytes in some areas, vascular congestion and sinusoidal enlargement were observed in the livers of group-2 mice. Only a mild sinusoidal enlargement was noted in group-3's liver. According to the data we obtained in our study, St. John's wort oil has protective and restorative effects especially on liver and intestinal mucosa.
\end{abstract}

\section{INTRODUCTION}

Methotrexate (MTX) is one of the chemotherapeutic agents which is used as an anticancer, anti-inflammatory and antimetabolite drug. Along with some malignancies, it is frequently used in the treatment of some inflammatory, hematological and autoimmune diseases such as psoriasis, dermatomyositis, sarcoidosis and rheumatoid arthritis in human $(1,2)$. Although MTX has a wide range of usage in treatments, it has negative effects especially on the liver such as inflammation, steatosis and fibrosis (1). Hepatotoxicity is a common side effect in treatment with MTX due to its metabolism in the liver (1,3-6). In addition, depending on individual sensitivity at low or high doses, MTX may cause various gastrointestinal system disorders characterized by abdominal pain, vomiting and diarrhea $(1,4,7)$. Inflammation of the intestinal mucosa, hemorrhage and peptic ulcers can be seen as gastrointestinal side effects of MTX (8).

St. John's wort (Hypericum perforatum) is a plant with yellow flowers and widely used as a phytotherapeutic remedy for treatment of depression and some other mental disorders (9-11). This plant contains a complex mixture of anthracene species (hypericin and pseudohypericin), hyperforin, flavonoids, procyanidins, vitamin C, carotene, and essential fatty acids. These ingreditens induce antiviral, antimalignant, antidepressant, antibacterial, antiinflammatory, and liver protective effects of St. John's wort (9). The aim of this study is to investigate the effects of St. John's wort oil on damaged liver and gastro intestinal tract of swiss albino mice exposed to MTX.

\section{MATERIAL and METHODS}

\section{Laboratory animal supply and adaptation to the environment}

In this study, 21 healthy swiss albino mice (aged 12 weeks), provided from Adana Veterinary Control Institute Experimental Animals Unit were used. The mice were fed with the pellet diets as ad libitum and were kept in a light-dark cycle for 12 hours a day and at a temperature of $24^{\circ} \mathrm{C} \pm 3^{\circ} \mathrm{C}$. They were acclimatized for 7 days before the study started.

\section{Application study}

In the 2nd week, mice were randomly divided into three groups: Group-1 is control group ( $n=7)$; Group-2 is MTXtreated group (Methotrexate $50 \mathrm{mg} / 5 \mathrm{ml}$, Koçak Farma, Turkey $(n=7)$; Group-3 is the MTX and St. John's wort oil treated group (St. John's wort oil, $50 \mathrm{ml}$, Sahra, Turkey) (n=7). Pellet feed + water was administered to the group-1. The MTX (20 mg/kg) was given intraperitoneally as a single dose on the 1 st day and pellet feed+water daily for 7 days to the group-2. The MTX (20 mg/kg) was administered intraperitoneally as a single dose on the $1 \mathrm{st}$ day; St. John's wort oil $(4 \mathrm{ml} / \mathrm{kg})$ was given by gavages into the stomach daily for 7 days and pellet feed+water daily for 7 days to the group-3. 24 hours after the 
last St. John's wort oil given, anesthesia was provided with ketamine $(40 \mathrm{mg} / \mathrm{kg}$ ) and the animals were decapitated.

\section{Histopathological examination}

Following the necropsy, the gastrointestinal mucosa samples and the liver tissue samples were collected for histopathological evaluation and fixed in 10\% neutral buffered formalin solution. The tissue samples were processed routinely, embedded in paraffin. Sections $(5 \mathrm{~mm})$ were taken from paraffin-embedded tissues, stained with haematoxylin-eosin (HE) and examined under microscope (Olympus CX41).

\section{RESULTS}

Group-1 showed no histopathological changes in liver (Figure 1a). In periportal areas, mononuclear cell infiltrations and locally degenerative changes; in vessels, vascular congestion, sinusoidal enlargement and thrombotic changes; in some areas, bile duct hyperplasia, megalocytosis in hepatocytes were observed in the livers of group- 2 mice (Figure 1b). No significant pathological findings were noted in the livers of group-3 mice, except for mild sinusoidal enlargement (Figure 1c).

In the histopathological examination of the gastric mucosa, no pathological changes were found in the the mice of the all groups. In the histopathological examination of the intestinal mucosa, no pathological changes were found in the mice of the group-1 (Figure 2a), but significant hyperplasia and mononuclear cell infiltrations in lamina propria were observed in the mice of the group-2 (Figure $2 \mathrm{~b}$ ). In the intestinal mucosa of mice of the group-3, there was no pathological changes finding similar to the mice of the group-1 (Figure 2c).

\section{DISCUSSION}

MTX is a chemotherapeutic remedy that has been used as an anticancer drug for many years and has also used as antimetabolite drug in the treatment of autoimmune chronic inflammatory diseases $(2,12)$. It has been reported that the toxicity caused by MTX is due to free oxygen radicals and hydrogen peroxide (12). Although MTX-related toxicities are common in kidney, bone marrow, and digestive organs, the most important complication of MTX is hepatotoxicity $(2,3)$. The main reason of the destruction of liver is oxidative stress due to MTX usage. (3). Studies on liver report that MTX usage causes enlargement of sinusoids, vascular congestion, mononuclear cell infiltration especially in portal areas, degeneration and fibroblast activation in portal areas, formation of heterochromatic hepatocytes (1,2). A study states that MTX treatment for 4 years induces rheumatoid arthritis and different degrees of fibrosis in liver (13). In this study, similar to other studies, mononuclear cell infiltrations, locally degenerative changes in the periportal area, vascular congestion and sinusoidal enlargement, thrombotic changes in the vessels, bile duct hyperplasia, megalocytosis in
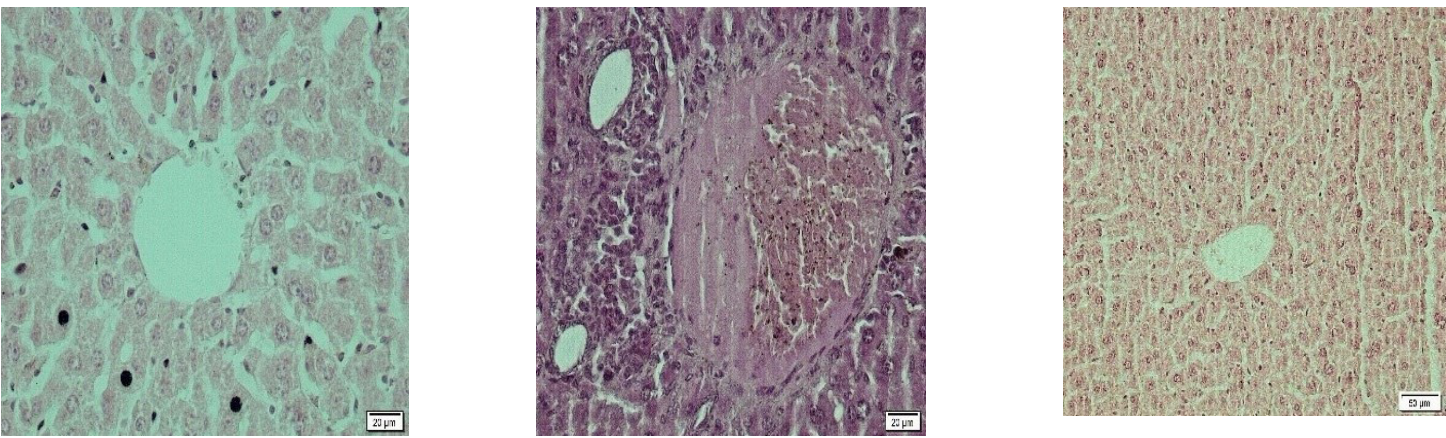

Figure 1. Microscopic view of livers of swiss albino mice. Group-1 mice, H.E., bar=20 $\mu \mathrm{m}$ (a). Mononuclear cell infiltration, thrombotic changes in the vessels and bile duct hyperplasia in the periportal area, group-2 mice, H.E., bar $=20 \mu \mathrm{m}$ (b). No significant pathological finding in the group-3 mice, H.E., bar=50 $\mu \mathrm{m}$ (c).
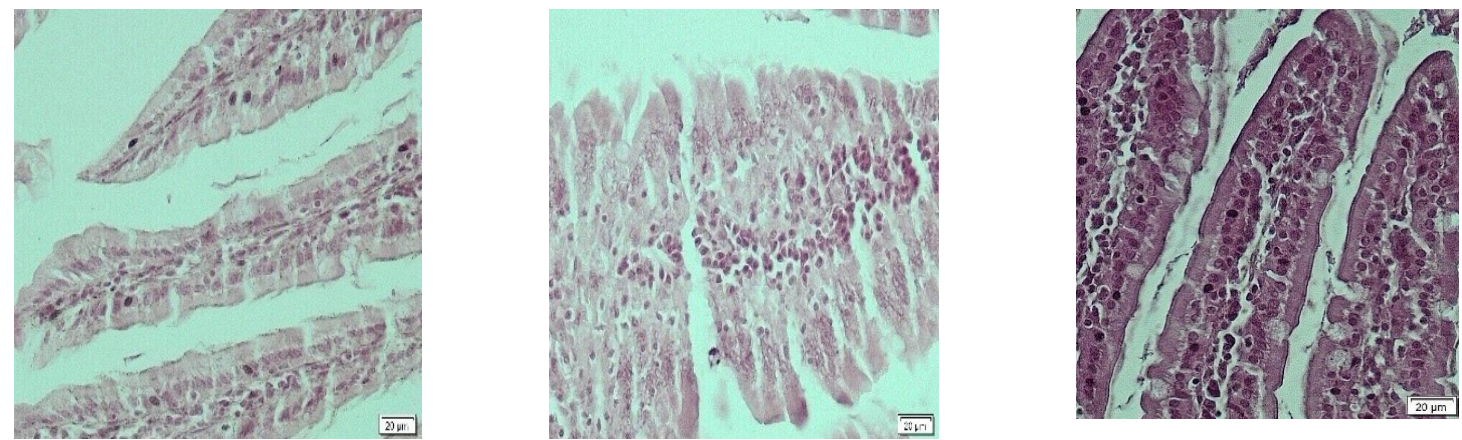

Figure 2. Histopathological appearance of intestinal mucosa of swiss albino mice. A section of the group-1 mice, H.E., bar $=20 \mu \mathrm{m}$ (a). A section of the group-2 mice, significant hyperplasia, H.E., bar=20 $\mu \mathrm{m}$ (b). A section of the group-3 mice, no any significant pathological finding similar to the mice of the group-1, H.E., $\mathrm{bar}=20 \mu \mathrm{m}(\mathrm{c})$. 
hepatocytes in some areas were seen only in group-2 mice. However, fibrosis was not occured in the liver. The other groups showed no pathological findings in livers. Only mild sinusoidal enlargement was noted in the group-3 mice. The absence of a prominent pathological finding in the group-3 mice was interpreted as the protective feature of St. John's wort oil for the liver. Accordingly, St. John's wort has been widely used in the treatment of many diseases for centuries with its antioxidant, anticancer, antidepressant, antimicrobial, antiinflammatory, analgesic, and hepatoprotective effects. This situation has also questioned the effectiveness and reliability of the plant over time, scientific and clinical studies have been carried out in this direction and different results have been obtained (10,14-16).

The digestive tract mucosa is highly sensitive to the effects of MTX (4). The inflammation of the intestinal mucosa, mucosal hemorrhages, and peptic ulcers are seen as gastrointestinal side effects of MTX, in addition, lethal mucosal necrosis is rarely occurs (8). In a case report, mouth and gastrointestinal tissue damage together with diarrhea were observed in patients with rheumatoid arthritis using low-dose $(2.5 \mathrm{mg} /$ day $)$ and high-dose $(7.5 \mathrm{mg} /$ day) of MTX. In addition, gastrointestinal disturbances have also been seen in patients taking MTX at least three times a week (17). In the present study, according to pathological examination of the gastric mucosa, no pathological findings were found in the the mice of the all groups. In the histopathological examination of the intestinal mucosa, there was no pathologic findings in the mice of the group-1, while significant hyperplasia and mononuclear cell infiltrations in lamina propria were observed in the mice of group-2. In the intestinal mucosa of mice of the group-3, there was no pathological findings similar to the mice of the group-1. Although gastric mucosa showed no pathological changes, pathological findings occured in intestinal mucosa with a single dose of MTX. However, it was interpreted that these pathological findings did not occur in the group-3 mice, which may be due to antioxidant, anti-inflammatory and protective effects of the St. John's wort oil.

\section{CONCLUSION}

According to the data we obtained in our study, St. John's wort oil has protective and restorative effects especially on liver and intestinal mucosa if it is used consciously. Nevertheless, considering that different results are obtained in the different clinical studies, we think that it would be appropriate to carry out more experimental studies with St. John's Wort.

\section{DECLARATIONS}

\section{Ethics Approval}

Ethics committee approval was received for this study from the Animal Research Ethics Committee of Adana Veterinary Control Institute (2019-4/807).

\section{Conflict of Interest}

The authors declare that they have no competing interests.

\section{Author Contribution}

Idea, concept, design, supervision, materials, writing and literature review: MS Seğmenoğlu

Analysis and interpretation: $\mathrm{H}$ Ak1llı
Data collection and processing: MS Seğmenoğlu, H Akıllı

\section{Data Availability}

The data that support the findings of this study are available from the corresponding author upon reasonable request.

\section{REFERENCES}

1. Kocaman N, Çolakoğlu N. Effects of repeated doses administration of methotrexate on rat liver tissue. Firat Med Journal. 2013;18(3):141-145.

2. Kocaman N, Dabak DÖ. Investigation of the protective effects of silymarin on the methotrexate-induced hepatotoxicity in rats. Firat Med Journal. 2019;33(2):67-72.

3. Armağan $\dot{\mathrm{I}}$. The role of oxidative stress in methotrexate-induced damage in liver and kidney of rats. Med J SDU. 2015;22(4):151-155.

4. Gaies E, Jebabli N, Trabelsi S, Salouage I, Charfi R, Lakhal M, et al. Methotrexate side effects. J Drug Metab Toxicol. 2012;3:125.

5. Wade SD, Yoshida EM, Carruthers MN, Weinblatt ME. Transient elastography for monitoring for hepatotoxicity in rheumatoid arthritis patients on long-term methotrexate. J Clin Rheumatol. 2018;10:1097.

6. West SG. Methotrexate hepatoxicity. Rheumatic diseases clinics of North America. 1997;23:883-915.

7. Olsen EA. The pharmacology of methotrexate. J Am Acad Dermatol. 1991;25:306-318.

8. Tsukada T, Nakano T, Miyata T, Sasaki S. Life-threatening gastrointestinal mucosal necrosis during methotrexate treatment for rheumatoid arthritis. Case Rep Gastroenterol. 2013;7:470-475.

9. Greeson JM, Sanford B, Monti DA. St. John's wort (Hypericum perforatum): a review of the current pharmacological, toxicological, and clinical literatüre. Psychopharmacology. 2001;153(4):402-14.

10. Hişıl Y, Şahin F, Omay SB. Composition of Hypericum perforatum $\mathrm{L}$. and its medical importance. UHOD. 2005;15(4):212-218.

11. Sarris J. St. John's wort for the treatment of psychiatric disorders. Psychiatr Clin North Am. 2013;36(1):65-72.

12. Güven E, Erişgin Z, Tekelioğlu Y. Histopathological effects of shilajit on methotrexate-induced testicular damage in rats. Kocatepe Medical Journal. 2017;18:1-6.

13. Albrecht K, Müller-Ladner U. Side effects and management of side effects of methotrexate in rheumatoid arthritis. Clin Exp Rheumatol. 2010;28:95-101.

14. Aksu Ö, Altınterim B. St. John's Worth (Hypericum perforatum) and hypericin. Bilim ve Gençlik Derg. 2015;3(1):5864.

15. Kurt H, Özbayer C, Değirmenci İ, Saadat SM, Üstüner 
MC, Köroğlu ZÖ, et al. Protective effects of Hypericum perforatum oil on indomethacin-induced gastric mucosal damage. Bozok Med J. 2016;6(3):62-8.

16. Yalçın S, Boğa Ö, Pekmezekmek AB. The role of St John's Wort (Hypericum perforatum) and orphanin interaction in depression treatment. Arşiv Kaynak Tarama Dergisi. 2015;24(4):531-541.

17. Teke HÜ, Özen M. Low-dose methotrexate induces pancytopenia in rheumatoid arthritis patients: are the risk factors predictors for physicians?. Turk J Phys Med Rehab. 2014;60:54-7. 